\title{
The relationship between visceral fat thickness and bone mineral density in sedentary obese children and adolescents
}

\author{
Ismael Forte Freitas Júnior ${ }^{1,5}$, Jefferson Rosa Cardoso ${ }^{2,5}$, Diego G Destro Christofaro ${ }^{3,5}$, Jamile Sanches Codogno ${ }^{4,5}$, \\ Augusto César Ferreira de Moraes $5,6,7,8$ and Rômulo Araújo Fernandes ${ }^{1,5,9^{*}}$
}

\begin{abstract}
Background: Among adults, obesity has been positively related to bone mineral density. However, recent findings have pointed out that abdominal obesity could be negatively related to bone density. The above mentioned relationship is not clear among pediatric populations. Therefore, this cross-sectional study analyzed the relationship between thickness of abdominal adipose tissue and bone mineral variables in sedentary obese children and adolescents.

Methods: One hundred and seventy five obese children and adolescents (83 male and 92 female) with ages ranging from 6 to 16 years-old were analyzed. Bone mineral content and density were estimated by dual-energy X-ray absorptiometry and ultrasound equipment which estimated the thickness of the abdominal adipose tissue. Pubertal stage was self-reported by the participants.

Results: The mean age was $11.1(\mathrm{SD}=2.6)$. Thickness of the abdominal adipose tissue was negatively related to bone mineral density $\left(r=-0.17\left[r_{95 \% \mathrm{Cl}}:-0.03 ;-0.32\right]\right)$, independent of gender, pubertal stage and other confounders $\left(\beta=-0.134 \pm 0.042\left[\beta_{95 \% c 1:}-0.217 ;-0.050\right]\right)$.

Conclusions: In sedentary obese children and adolescents abdominal obesity is negatively related to bone mineral density, suggesting a potential link between abdominal obesity and osteoporosis.
\end{abstract}

Keywords: Child, Adolescents, Obesity, Bone size, Bone density, Ultrasonography

\section{Background}

In modern society osteoporosis is a highly occurring disease and constitutes a public health concern due to its impact on public costs [1]. Early life has been pointed out as a crucial period in the development of osteoporosis. Childhood and adolescence are phases of the human development during which the adult bone mass density is determined and, therefore, problems during this period of life could compromise bone health in adulthood [2].

Worldwide, children and adolescents are widely affected by obesity and its comorbidities [3-6]. Despite

\footnotetext{
* Correspondence: romulo@fct.unesp.br

${ }^{1}$ Department of Physical Education, UNESP Univ Estadual Paulista, Presidente Prudente, Brazil

${ }^{5}$ Group of Scientific Research Related to Physical Activity. Department of Physical Education, UNESP Univ Estadual Paulista, Presidente Prudente, Brazil Full list of author information is available at the end of the article
}

these related comorbidities, overweight/obesity has been associated with a lower occurrence of osteoporosis in adulthood. However, body weight is composed of lean and fat mass and the actual effect of the adipose tissue on bone mineral density (BMD) is not clear.

Moreover, the distribution of the adipose tissue could be a relevant confounder in this complex process that links obesity to osteoporosis. Recently, Bhupathiraju et al. [7] analyzing Porto Rican adults (47-79 years) observed that a higher abdominal fat mass (in $\mathrm{kg}$ ) is related to a lower BMD, but the amount of visceral and subcutaneous abdominal adipose tissue were not assessed. Furthermore, there is an absence of data about this issue in pediatric populations. Understanding the relationship between pediatric obesity and bone health is relevant for health professionals [8-10], because childhood and adolescence are two critical periods in the prevention and development

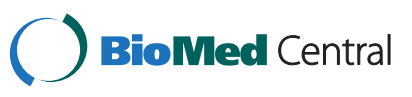


of diseases in adulthood (e.g. arterial hypertension, diabetes mellitus and dyslipidemias) [2,8-10]. So, the purpose of this study was to analyze the relationship between abdominal adipose tissue and BMD in obese children and adolescents.

\section{Methods}

Participants

The present study was approved by the Ethical Research Expert Committee of the Universidade Estadual Paulista in Presidente Prudente, Brazil (\# 087/2008). The sample size was estimated through an equation for correlation's coefficients, which took into consideration a power of $80 \%$ and significance of $5 \%(\mathrm{z}=1.96)$. A previous study analyzed the relationship between BMD and intraabdominal adipose tissue (IAAT) and identified correlations ranging from $r=-0.31$ to $r=-0.65$ [11]. Thus, the lowest coefficient was inserted in the equation and the minimum sample size indicated was 80 subjects.

The subjects were invited, through television and newspaper advertising, to participate in this study. The participants contacted the researchers by phone and an appointment was made in order to take measurements at the Campus of the University. Initially, the diagnosis of obesity was based on body mass index cut-off points, adjusted by sex and age, developed by Cole et al. [12]. After a positive diagnosis of obesity, some inclusion criteria were also used to select the sample: i) aged between 6 and 17 years [chronological age computed taking into account their birthday and the measurement day]; ii) no engagement in regular physical activity within the three months prior to the study (established via a face-to-face interview with the child/adolescent and their parents); iii) a self-report of no diagnosis of either cardiovascular disease or regular medicine use and iv) a consent form signed by parents/guardians to participate in the study. Finally, one hundred and seventy five obese children and adolescents (83 male and 92 female) with ages ranging from 6 to 16 years-old were included in the study.

\section{Bone mineral density}

Body composition and BMD were estimated by Dual-energy X-ray absorptiometry (DEXA) (Lunar DPX-NT; General Electric Healthcare, Little Chalfont, Buckinghamshire [software version 4.7]). The method estimated the percentage of body fat (\%BF) and trunk fat mass (TFM [kg]), as well as, whole-body bone mineral density (BMD $\left.\left[\mathrm{g} / \mathrm{cm}^{2}\right]\right)$. All data were collected by trained staff and all measurements were taken at the laboratory of the University, in a temperature controlled room. Each morning, before the first measurement, the DEXA equipment was calibrated by the same researcher according to the references provided by the manufacturer.

\section{Ultrasound measures of the abdominal adipose tissue}

Ultrasound equipment (Toshiba Aplio Model Tochigi-ken, Japan) was used to measure the thickness of adipose tissue in the abdominal region. IAAT was defined as the distance between the internal face of the rectus abdominal muscle and the anterior wall of the aorta. Thus, the thickness (in $\mathrm{cm}$ ) of IAAT was estimated. For statistical analysis, the values of IAAT were stratified into tertile (Tertile-1 [bottom]; middle Tertile-2 [middle]; Tertile-3 [top]). All measurements were taken by a trained physician, in a Hospital, in a room with a constantly controlled temperature. Each morning, before any measurements were taken, the device was calibrated and, according to the reference values provided by the manufacturer, the tests presented high reliability.

\section{Pubertal stage}

Pubertal stage was self-assessed by the participants. The subjects received a standardized series of drawings to assess their own pubertal development (Girls: drawings with five stages of breast and female pubic hair development; Boys: drawings with five stages of genitalia and male pubic hair development) $[13,14]$. These scales have been previously validated in Brazilian pediatric populations $[15,16]$. The drawing had appropriate descriptions accompanying it. The results were placed by each subject in a locked box to guarantee the integrity and anonymity of the subjects, and only the main researcher had access to them. All pubertal measurements were performed at the University laboratory.

\section{Statistical analysis}

The Kolmogorov-Smirnov (K-S) test, used to test the distribution of the numerical variables and logarithm transformation, was used in variables of non-parametric distribution. Mean, median, 95\% confidence interval (95\% CI), standard deviation (SD) and interquartile range $\left(\mathrm{P}_{75}-\mathrm{P}_{25}\right)$ were used as descriptive statistics. For analysis of variance (ANOVA), homogeneity assumption was assessed in advance. If the assumption was in accordance, test $\mathrm{F}$ was performed and, in cases of statistical differences, the tertiles of IAAT were tested through Tukey's multiple comparisons. Pearson's correlation was used to analyze the relationship between the numerical variables. In cases of moderate-high correlations, multivariable models were elaborated using linear regression and, therefore, the correlations between BMD and IAAT were adjusted by potential confounders (sex, age, total body fatness, trunk fatness, height and pubertal stage). Chi-square test analyzed associations between categorical variables and Yates correction was applied in $2 \times 2$ contingence tables. Statistical significance was set at $5 \%$ and statistical software BioEstat version 5.0 was used for all analyses. 


\section{Results}

General characteristics of the analyzed sample are presented in Table 1. The K-S test indicated that most of the numerical variables were under non-parametric distribution, except for weight, height and \%BF. Male gender made up $47.4 \%$ of the sample and there was a similarity between the numbers of boys and girls $(P=$ $0.496)$. The mean age was $11.1(\mathrm{SD}=2.6)$, and ranged from 6 to 16 years-old and the proportion of children and adolescents was similar $(P=0.112)$.

There were more children and adolescents at initial pubertal stage $(40 \%)$ than final pubertal stage $(24.6 \%)$ $(P=0.037)$. Children and adolescents at a higher pubertal stage had a higher BMD (Stage- $1=0.96 \pm 0.07 \mathrm{~g} / \mathrm{cm}^{2}$; Stages $2-3=1.06 \pm 0.10 \mathrm{~g} / \mathrm{cm}^{2} ;$ Stages $4-5=1.16 \pm 0.10 \mathrm{~g} / \mathrm{cm}^{2}$; ANOVA $P=0.001)$. Boys and girls had similar values of $\operatorname{BMD}\left(1.05 \pm 0.11 \mathrm{~g} / \mathrm{cm}^{2}\right.$ and $1.04 \pm 0.12 \mathrm{~g} / \mathrm{cm}^{2}[P=0.630]$, respectively). Adolescents presented higher BMD than children $\left(6-10\right.$ years $=0.95 \pm 0.05 \mathrm{~g} / \mathrm{cm}^{2}$ and $11-17$ years $=$ $1.12 \pm 0.10 \mathrm{~g} / \mathrm{cm}^{2}[P=0.001]$, respectively).

Age $(r=0.80)$, weight $(r=0.78)$, height $(r=0.70)$, TFM $(r=0.63)$ and pubertal stage $(r=0.66)$ were significantly related to BMD, except for \%BF values $(r=0.09)$. In the multivariable model, IAAT was negatively related to BMD, independent of other confounders (Table 2). IAAT was stratified into tertiles and the values of BMD

Table 1 General characteristics of obese children and adolescents $(\mathbf{n}=\mathbf{1 7 5})$

\begin{tabular}{|c|c|c|c|}
\hline Variables & Mean (SD) & $(95 \% \mathrm{Cl})$ & Median $\left(\mathrm{P}_{75}-\mathrm{P}_{25}\right)$ \\
\hline Age (years) & $11.1(2.6)$ & $(10.7 ; 11.5)$ & $11(4)$ \\
\hline Weight (kg) & $66.8(19.2)$ & $(63.9 ; 69.7)$ & $64.1(25.3)$ \\
\hline Height (m) & $1.50(0.12)$ & $(1.48 ; 1.52)$ & $1.50(0.20)$ \\
\hline$\% B F$ & $45.4(5.2)$ & $(44.6 ; 46.2)$ & $45(7.2)$ \\
\hline TFM (kg) & $13.8(5.1)$ & $(13.1 ; 14.5)$ & $13.4(6.3)$ \\
\hline IAAT (cm) & $4.35(1.5)$ & $(4.13 ; 4.58)$ & $4.1(1.8)$ \\
\hline $\operatorname{BMD}\left(\mathrm{g} / \mathrm{cm}^{2}\right)$ & $1.04(0.12)$ & $(1.03 ; 1.06)$ & $1.03(0.19)$ \\
\hline Categorical Variables & n (\%) & $P$ & \\
\hline Gender & & 0.496 & \\
\hline Male & $83(47.4)$ & & \\
\hline Female & $92(52.6)$ & & \\
\hline Pubertal stage & & 0.037 & \\
\hline Stage 1 & $70(40)$ & & \\
\hline Stages 2-3 & $62(35.4)$ & & \\
\hline Stages $4-5$ & $43(24.6)$ & & \\
\hline Age & & 0.112 & \\
\hline $6-10$ years & $77(44)$ & & \\
\hline $11-17$ years & $98(56)$ & & \\
\hline
\end{tabular}

$\mathrm{SD}=$ standard-deviation; $95 \% \mathrm{Cl}=95 \%$ confidence interval; $\% \mathrm{BF}=$ percentage of body fatness; Trunk-BF = trunk body fatness; IAAT = intra-abdominal adipose tissue; $\mathrm{BMD}=$ bone mineral density; TFM = trunk fat mass.
Table 2 Relationship between intra-abdominal adipose tissue and variables related to the bones of children and adolescents

\begin{tabular}{|c|c|c|}
\hline \multicolumn{2}{|c|}{ Univariate } & Multivariable model \\
\hline$r\left(r_{95 \% \mathrm{Cl}}\right)$ & $\beta_{\text {adjusted }} \pm$ SEM & $\left(\beta_{95 \% C l}\right)$ \\
\hline
\end{tabular}

$\mathrm{BMD}^{*}$

IAAT* $^{*}-0.17(-0.03 ;-0.32) \quad-0.134 \pm 0.042 \quad(-0.217 ;-0.050) \quad 0.002$

* = numerical variable under logarithm transformation; $\beta_{\text {adjusted }}=$ model adjusted by sex, age, height, total body fatness, trunk fatness and pubertal stage; $\mathrm{BMD}=$ bone mineral density; IAAT = intra-abdominal adipose tissue; $\mathrm{SEM}=$ standard error mean; $95 \% \mathrm{Cl}=95 \%$ confidence interval.

(Figure 1) were compared between them. Obese adolescents in the highest IAAT tertile presented lower BMD than those in the lowest IAAT tertile.

\section{Discussion}

A cross-sectional study, which identified that IAAT is inversely related to BMD. In this pediatric sample, the mean of IAAT was $4.35 \mathrm{~cm}$ which seems a normal value, because it was similar to another group of sedentary obese children and adolescents without non-alcoholic fat liver disease (mean value of $4.1 \mathrm{~cm}$ ) [17]. On the other hand, the same group of obese children and adolescents had a significant decrease of $1.6 \mathrm{~cm}$ after one year of exercise intervention [17], supporting the relevance of the sedentary lifestyle as an inclusion criteria and evidencing the potential of prolonged engagement of physical exercise in combating comorbidities related to abdominal obesity $[8,9]$. The inclusion of the sedentary lifestyle was also important because there is a positive relationship between increased habitual physical activity and BMD [18].

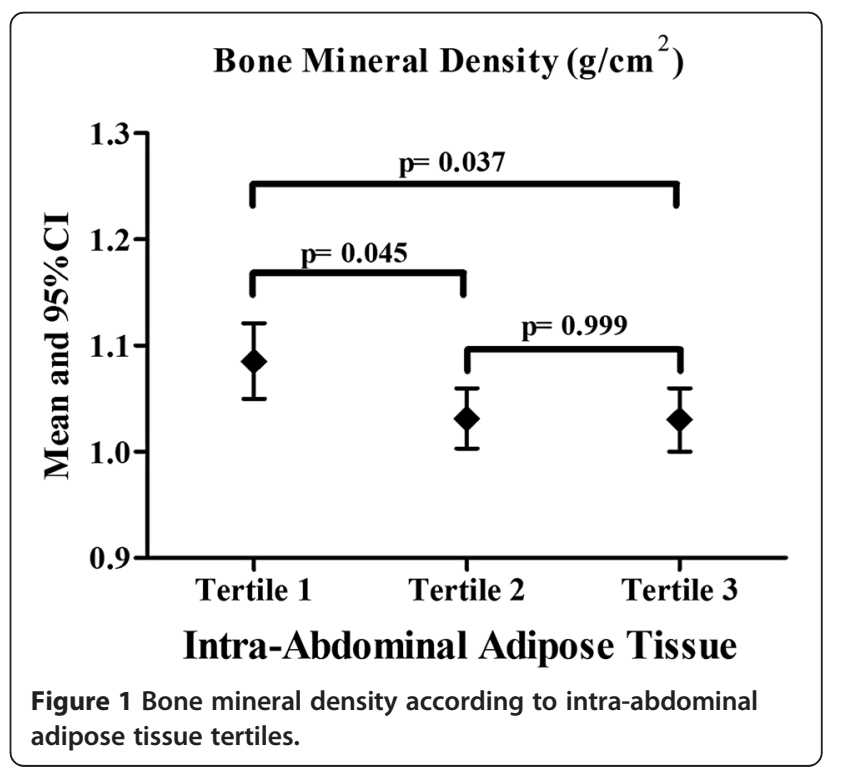


Gender is an important variable related to skeletal formation. Male adolescents, more than girls, are affected by biological processes that accelerate bone development [2]. In the final stages of adolescence, boys are taller and have a higher bone mineral density [2]. Through childhood and adolescence, when compared to the female gender, boys have an increased likelihood of practicing sports [8,9], which are related to bone development. Moreover, during adulthood, hormonal characteristics of male obesity may exert deleterious effects on bone microarchitecture [19]. Therefore, the inclusion of gender as a potential confounder constitutes a methodological strength, because it indicates that IAAT is inversely related to BMD independent of this important confounder.

Agreeing with previous studies, in this sample there was a positive relationship between body weight/adiposity and BMD [11,20]. Indeed, obese subjects, from an early age, have increased bone density, mainly due to the stress occasioned by the increased weight on bone tissue that causes deformation and, hence, leads to bone remodeling [2]. Similarly, the same mechanical/biochemical process offers support to the idea that sports with impact are important tools in the promotion of adequate bone health in adolescents [2]. It is noteworthy that although obesity is positively related to $\mathrm{BMD}$, more recent findings suggest that bone quality is compromised in obese subjects [21].

On the other hand, our findings point out that body fatness distribution should be considered as a potential confounder in this relationship, because increased IAAT was inversely related to $\mathrm{BMD}$, independent of general obesity. Previous studies involving anthropometric (waist-to-hip ratio) [20] and DXA variables (abdominal fatness in $\mathrm{kg}$ ) [7] identified similar relationship patterns in children and adults, respectively.

The inverse relationship between IAAT and BMD could be based on the action of adipokines produced by adipose tissue over growth mediators related to bone development. Nemet et al. [22] identified, in a longitudinal design, that the practice of very high intensity physical exercise simultaneously caused a significant increase in proinflammatory markers (tumor necrosis factor - alpha) and a subsequent decrease in growth mediators, such as insulin-like-growth-factor-I. Similarly, the adipose tissue located in the abdominal region (mainly the visceral one) has a special role in the release of adipokines into the bloodstream [23]. Therefore, it is possible to believe that IAAT could be a risk factor related to a harmful effect in bone remodeling and in turn to a risk factor of osteoporosis in adulthood.

Visceral adipose tissue is related to insulin resistance and insulin plays a role in the proliferation of osteoblasts. Thus, decreased insulin action may be one of the possible mechanisms by which obesity affects bone mass. In agreement, in a recent study, increased insulin concentration and HOMA-IR were considered negative predictors of bone mineral density in adolescents [24]. However, this is a recent finding that needs further top research focusing on the understanding of the physiological common mechanisms behind this association.

Our study has positive points, such as: (i) the sample size calculation; (ii) the use of adequate techniques to measure body composition/IAAT. On the other hand, limitations should be recognized: (i) the cross-sectional design (absence of causality statements), (ii) an absence of measurements relating to the intake of calcium and vitamin $\mathrm{D}$ and (iii) an absence of pro-inflammatory adipokines. Moreover, there were correlations of low magnitude between BMD and IAAT, indicating that other variables are important in this relationship and, therefore, further studies are necessary to identify them.

\section{Conclusions}

In summary, our findings indicate that abdominal obesity negatively affects the bone density of obese children and adolescents, indicating that abdominal obesity could be a determinate in the development of osteoporosis in adulthood. Further studies should analyze whether this negative effect also occurs in non-obese youth.

\section{Abbreviations}

BMD: Bone mineral density; IAAT: Intra-abdominal adipose tissue; BMI: Body mass index; TFM: Trunk fat mass; DEXA: Dual-energy X-ray absorptiometry; BF: Body fat; TFM: Trunk fat mass; K-S: Kolmogorov-smirnov; SD: Standard deviation; ANOVA: Analysis of variance; $\mathrm{Cm}$ : Centimeters; SEM: Standard-error mean.

\section{Competing interesting}

The authors declare that there is no conflict of interest.

\section{Authors' contributions}

IFFJ: (1) the conception and design of the study, acquisition of data and analysis and interpretation of data, (2) drafting the article and revising it critically for important intellectual content, (3) final approval of the version to be submitted. DGDC: (1) revising it critically for important intellectual content, (2) final approval of the version to be submitted. JRC: (1) revising it critically for important intellectual content, (2) final approval of the version to be submitted. ACFM: (1) revising it critically for important intellectual content, (2) final approval of the version to be submitted. JSC: (1) revising it critically for important intellectual content, (2) final approval of the version to be submitted. RAF: (1) the conception and design of the study (2) revising it critically for important intellectual content, (3) final approval of the version to be submitted. All authors read and approved the final manuscript.

\section{Author details}

${ }^{1}$ Department of Physical Education, UNESP Univ Estadual Paulista, Presidente Prudente, Brazil. ${ }^{2}$ Department of Physical Therapy, Universidade Estadual de Londrina - UEL, Londrina, Brazil. ${ }^{3}$ Department of Physical Education, Universidade do Oeste Paulista, Presidente Prudente, Brazil. ${ }^{4}$ Department of Physical Education, UNESP Univ Estadual Paulista, Rio Claro, Brazil. ${ }^{5}$ Group of Scientific Research Related to Physical Activity. Department of Physical

Education, UNESP Univ Estadual Paulista, Presidente Prudente, Brazil. ${ }^{6}$ School of Medicine (FMUSP) of the Universidade de São Paulo, São Paulo, Brazil.

${ }^{7}$ GENUD - Growth, Exercise, Nutrition and Development - Faculty of Health Sciences of the University of Zaragoza, Zaragoza, Spain. ${ }^{8}$ GEPECIN - Research Group in Nutritional Sciences, Catholic Pontificate University/PR, Maringá, Brazil. ${ }^{9}$ Universidade Estadual Paulista, Street Roberto Simonsen, 305, Presidente Prudente ZIP Code: 19060-900SP, Brazil. 
Received: 11 September 2012 Accepted: 12 March 2013

Published: 20 March 2013

\section{References}

1. National Osteoporosis Foundation: Strong voices for strong bones. Washington, DC: Available from: http://www.nof.org/files/nof/public/ content/file/63/upload/49.pdf (cited 01 March 2013).

2. Malina RM, Bouchard C, Bar-Or O: Growth, Maturation, and Physical Activity. 2nd edition. Human Kinetics: Champaign; 2004

3. Wang Y, Monteiro C, Popkin BM: Trends of obesity and underweight in older children and adolescents in the United States, Brazil, China, and Russia. Am J Clin Nutr 2002, 75:971-977.

4. Duncan S, Duncan EK, Fernandes RA, Buonani C, Bastos KD, Segatto AF, et al: Modifiable risk factors for overweight and obesity in children and adolescents from São Paulo. Brazil. BMC Public Health 2011, 11:585.

5. Christofaro DG, Ritti-Dias RM, Fernandes RA, Polito MD, Andrade SM, Cardoso JR, et al: High blood pressure detection in adolescents by clustering overall and abdominal adiposity markers. Arq Bras Cardiol 2011, 96:465-470

6. Fernandes RA, Freitas Júnior IF, Codogno JS, Christofaro DG, Monteiro HL, Roberto Lopes DM: Resting heart rate is associated with blood pressure in male children and adolescents. J Pediatr 2011, 158:634-637.

7. Bhupathiraju SN, Dawson-Hughes B, Hannan MT, Lichtenstein AH, Tucker KL: Centrally located body fat is associated with lower bone mineral density in older Puerto Rican adults. Am J Clin Nutr 2011, 94:1063-1070.

8. Fernandes RA, Christofaro DG, Casonatto J, Codogno JS, Rodrigues EQ, Cardoso ML, et al: Prevalence of dyslipidemia in individuals physically active during childhood, adolescence and adult age. Ara Bras Cardiol 2011, 97:317-323.

9. Fernandes RA, Zanesco A: Early physical activity promotes lower prevalence of chronic diseases in adulthood. Hypertens Res 2010, 33(8):926-931.

10. Sinaiko AR, Donahue RP, Jacobs DR Jr, Prineas RJ: Relation of weight and rate of increase in weight during childhood and adolescence to body size, blood pressure, fasting insulin, and lipids in young adults, The Minneapolis Children's Blood Pressure Study. Circulation 1999, 99:1471-1476.

11. Do Prado WL, De Piano A, Lazaretti-Castro M, De Mello MT, Stella SG, Tufik $S$, et al: Relationship between bone mineral density, leptin and insulin concentration in Brazilian obese adolescents. J Bone Miner Metab 2009, 27:613-619

12. Cole TJ, Bellizzi MC, Flegal KM, Dietz WH: Establishing a standard definition for child overweight and obesity worldwide: international survey. BM 2000, 320:1240-1243.

13. Marshall WA, Tanner JM: Variations in pattern of pubertal changes in girls. Arch Dis Child 1969, 44:291-303.

14. Marshall WA, Tanner JM: Variations in the pattern of pubertal changes in boys. Arch Dis Child 1970, 45:13-23.

15. Bojikianl LP, Massa M, Martini RH, Teixeira CP, Kissi MA, Böhme MT: Females' self-assessment of sexual maturation. Rev Bras Ativ Fis Saude 2002, 7:24-34

16. Martin RH, Uezu R, Parra SA, Arena SS, Bojikian LP, Böhme MT: Males selfassessment of sexual maturation using drawings and photos. Rev Paul Educ Fís 2001, 15:212-222.

17. Campos RM, de Piano A, da Silva PL, Carnier J, Sanches PL, Corgosinho FC, et al: The role of pro/anti-inflammatory adipokines on bone metabolism in NAFLD obese adolescents: effects of long-term interdisciplinary therapy. Endocrine 2012, 42:146-156.

18. Tobias JH, Steer CD, Mattocks CG, Riddoch C, Ness AR: Habitual levels of physical activity influence bone mass in 11-year-old children from the United Kingdom: findings from a large population-based cohort. J Bone Miner Res 2007, 22:101-109.

19. Bredella MA, Lin E, Gerweck AV, Landa MG, Thomas BJ, Torriani M, Bouxsein ML, Miller KK: Determinants of bone microarchitecture and mechanical properties in obese men. J Clin Endocrinol Metab 2012, 97:4115-4122.

20. Rhie YJ, Lee KH, Chung SC, Kim HS, Kim DH: Effects of body composition, leptin, and adiponectin on bone mineral density in prepubertal girls. J Korean Med Sci 2010, 25:1187-1190.

21. Shapses SA, Sukumar D: Bone metabolism in obesity and weight loss. Annu Rev Nutr 2012, 32:287-309.
22. Nemet D, Oh Y, Kim HS, Hill M, Cooper DM: Effect of intense exercise on inflammatory cytokines and growth mediators in adolescent boys. Pediatrics 2002, 110:681-689.

23. Huang PL: eNOS, metabolic syndrome and cardiovascular disease. Trends Endocrinol Metab 2009, 20:295-302.

24. Campos RM, Lazaretti-Castro M, Mello MT, Tock L, Silva PL, Corgosinho FC, et al: Influence of visceral and subcutaneous fat in bone mineral density of obese adolescents. Arq Bras Endocrinol Metabol 2012, 56:12-18.

doi:10.1186/1471-2431-13-37

Cite this article as: Júnior et al:: The relationship between visceral fat thickness and bone mineral density in sedentary obese children and adolescents. BMC Pediatrics 2013 13:37.

\section{Submit your next manuscript to BioMed Central and take full advantage of:}

- Convenient online submission

- Thorough peer review

- No space constraints or color figure charges

- Immediate publication on acceptance

- Inclusion in PubMed, CAS, Scopus and Google Scholar

- Research which is freely available for redistribution 